\title{
Diffraction Methods and Scale Transition Model used to study Evolution of Intergranular Stress and Micro-Damage Phenomenon during Elasto-Plastic Deformation
}

A. Baczmański ${ }^{1, a^{*}}$, S. Wroński $i^{1, b}$, E. Gadalińska ${ }^{2, c}$, Y. Zhao ${ }^{3, d}$, L. Le Joncour ${ }^{3, e}$, C. Braham ${ }^{4, f}$, C. Scheffzük $k^{6,7, g}$ and P. Kot ${ }^{1, h}$

${ }^{1}$ AGH-University of Science and Technology, WFilS, al. Mickiewicza 30, 30-059 Krakow, Poland

${ }^{2}$ Institute of Aviation, al. Krakowska 110/114, 02-256 Warszawa, Poland

${ }^{3}$ ICD-LASMIS, Université de Technologie de Troyes (UTT), 12 rue Marie Curie, 10004 Troyes, France

${ }^{4} \mathrm{PIMM}$, Arts et Métiers ParisTech (ENSAM), 151 Bd de l'Hôpital, 75013 Paris, France

${ }^{5}$ FLNP, Joint Institute for Nuclear Research, 141980 Dubna, Russia

${ }^{6}$ Karlsruhe Institute of Technology, Adenauerring 20b, 76131 Karlsruhe, Germany

aBaczmanski@fis.agh.edu.pl, 'Wronski@fis.agh.edu.pl, 'Elzbieta.Gadalinska@ilot.edu.pl,

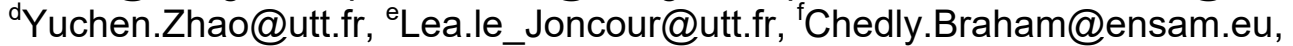

${ }^{9}$ Christian.Scheffzuek@kit.edu, hPrzemyslaw.Kot@fis.agh.edu.pl

Keywords: Polycrystalline Material, Yield Condition, Damage Process, Self-Consistent Model, Diffraction Measurements

\begin{abstract}
A methodology combining diffraction experiments and self-consistent calculations was used to study the mechanical behaviour of groups of grains within two-phase polycrystalline materials. In this work, an $\mathrm{Al} / \mathrm{SiC}_{\mathrm{p}}$ composite and duplex austenitic-ferritic steel are studied. The lattice strain evolution was determined from lattice strain measured in situ during tensile tests using neutron diffraction. The experimental results were used to study slip on crystallographic planes, localisation of stresses in polycrystalline grains and the mechanical effects of damage occurring during plastic deformation. For this purpose, a prediction made using the recently developed new version of the elasto-plastic self-consistent model was compared with the experimental data.
\end{abstract}

\section{Introduction}

Diffraction methods for lattice strain measurement provide useful information concerning the nature of grains behaviour during elastoplastic deformation. The main advantage of the diffraction methods is the possibility of studying mechanical properties of polycrystalline materials separately in each phase and groups of grains with a specific orientation. These methods enable an analysis of macrostress and microstress for multiphase and anisotropic materials. The multi-scale crystallographic models are very convenient for the study of elastoplastic properties on microscopic and macroscopic scales. Comparison of experimental data with model predictions allows us to understand the physical phenomena, which occur during sample deformation at the level of polycrystalline grains. Moreover, the micro and macro parameters of elasto-plastic deformation can be experimentally established. The main advantage of the methodology combining diffraction experiment and the self-consistent calculation is that the mechanical behaviour of polycrystalline groups of grains or different phases can be studied.

In this work, neutron diffraction was used to study in situ deformation of two phases in an $\mathrm{Al} / \mathrm{SiC}_{\mathrm{p}}$ composite and duplex stainless steels during tensile loading. The aim is to show the role 
of reinforcement in the partitioning of loads between phases in metal matrix composites (MMC). Next, the partitioning of the stresses between two phases of elasto-plastically deformed duplex steel is studied, and attention is paid to stress relaxation indicating damage processes. Interpretation of experimental results is done using the self-consistent model including prediction of damage process.

\section{Self-consistent model including damage prediction}

The lattice strains measured in situ during the diffraction experiment can be compared with calculations performed using self-consistent models in which the homogenization method based on the interaction of an ellipsoidal inclusion with the homogenous medium is considered [1]. In many works the theoretical results were obtained through the self-consistent model of elastoplastic deformation based on formalism proposed by Hill [2] and developed by Turner \& Tome [3]. This method was implemented for the interpretation of the diffraction experiment by Clausen et al. [4] and used in works such as [5, 6].

Another formulation of the self-consistent elastoplastic model was proposed by Lipinski \& Berveiller [7]. Despite the differences in the constitutive equations and homogenization scheme, in both self-consistent elastoplastic models the interaction of an ellipsoidal inclusion with the homogenous medium is approximated by the Eshelby tensor [1]. The model developed by Berveiller and Lipinski describes the behaviour of a polycrystalline material for large strains, taking the rotation of the crystal lattice into account. The latter method was used by many authors to predict elastoplastic deformation and texture evolution in polycrystalline materials [8$11]$.

Recently, the self-consistent model (version by Lipinski \& Berveiller) was developed to predict ductile micro-damage process [10]. To do this, the assumption of total energy equivalence [11] was applied at the grain scale and the effective total strain $\tilde{\varepsilon}_{i j}^{g}$ and the effective stress $\tilde{\sigma}_{i j}^{g}$ tensors were introduced for each grain g:

$\tilde{\varepsilon}_{i j}^{g}=\varepsilon_{i j} \sqrt{1-d^{g}}$ and $\tilde{\sigma}_{i j}^{g}=\frac{\sigma_{i j}^{g}}{\sqrt{1-d^{g}}}$

where: $d^{g}$ is a scalar damage variable which describes damage at a grain scale.

Assuming that $d^{g}$ in Eq. 1 depends on total strain and stress tensors, the expression for tangent moduli and strain concentration tensor were defined for the damaged material using comparison with the equivalent undamaged material $[11,12]$. In this approach also the influence of damage on the evolution of critical resolved shear stress (CRSS, denoted by $\tau_{c}$ ) and hardening parameter $(\mathrm{H})$ are taken into account (for details see [11]). The physical consequences of the damage process occurring in a given grain are a decrease in localized stress and an increase in total deformation, which in turn will lead to softening of the grain.

Finally, to describe micro-damage process occurring in the grain $\mathrm{g}$ the variation of the $d^{g}$ function has to be established, which is defined by $\dot{d}^{g}$ rate according to the following relation:

$$
\dot{d}^{g}=\xi^{p h}\left(\varepsilon_{e q}^{g}-\varepsilon_{0}^{p h}\right)_{+}^{n^{p h}}\left(\dot{\varepsilon}_{e q}^{g}\right)_{+}
$$

where: $\varepsilon_{e q}^{g}$ is the second invariant of the total strain tensor for a grain $g$ and $\varepsilon_{0}^{p h}, n^{p h}, \xi^{p h}$ are phase-dependent parameters (denoted by the superscript ph), $(\ldots)_{+}$are the Macaulay brackets, which means the positive part of the quantity $\varepsilon$, i.e. $(x)_{+}=x$ if $x>0$ and $(x)_{+}=0$ if $x \leq 0$. 


\section{Sources of hardening in $\mathrm{Al} / \mathrm{SiC}_{\mathrm{p}}$ composite}

The experiments analysed in this work were performed for the $\mathrm{Al} / \mathrm{SiC}_{\mathrm{p}}$ metal matrix composite comprising 2124 aluminium alloy and ultrafine particles of silicon carbide (size of $0.7 \mu \mathrm{m}$ ). It was produced by a powder metallurgy route comprising a blending of the alloy powder and reinforcement, compaction, and consolidation by hot isostatic pressing. The amount of the reinforcement particles was $17.8 \%$ by volume.
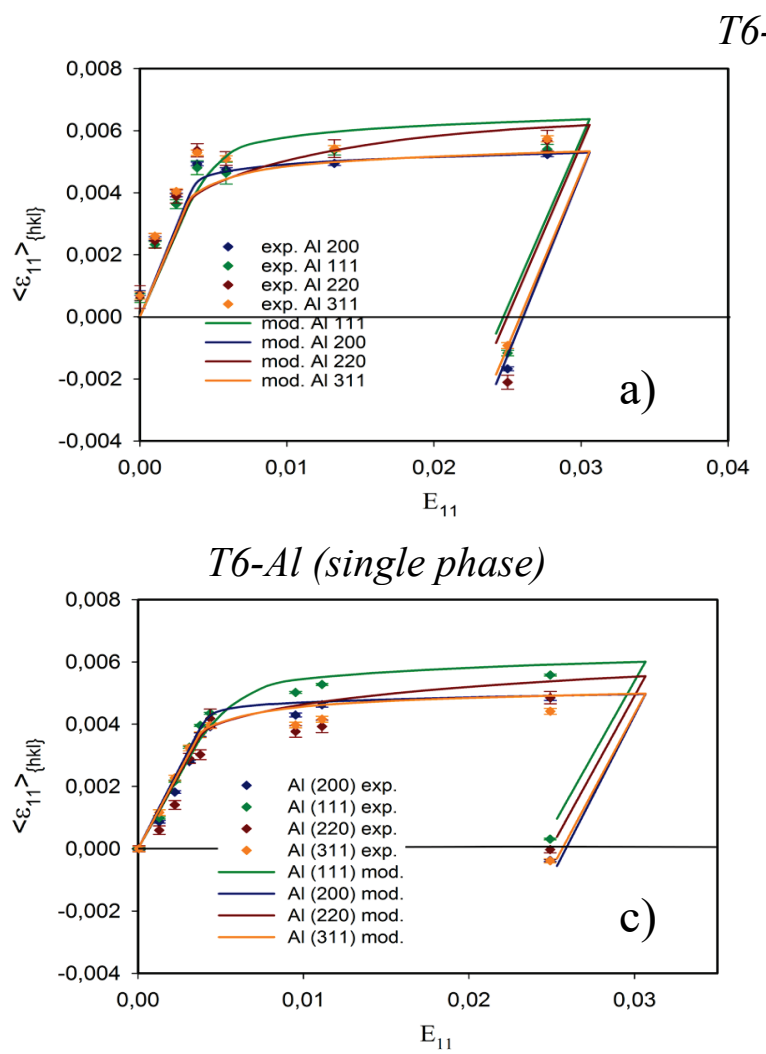

6- $\mathrm{Al} / \mathrm{SiC} \mathrm{C}_{\mathrm{p}}$

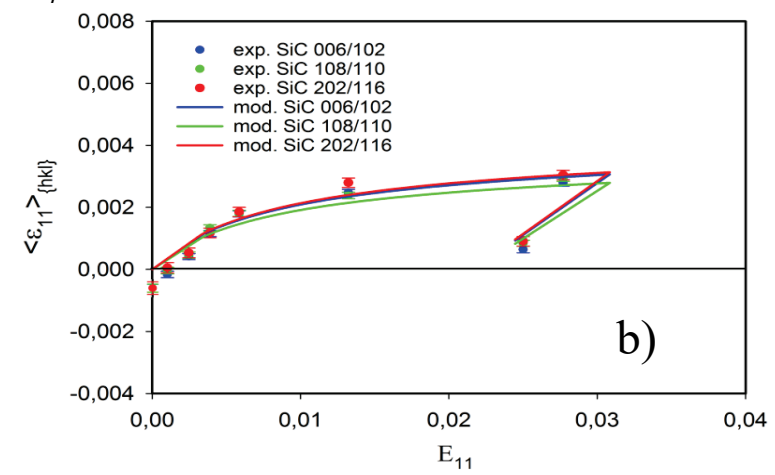

Fig. 1: Lattice strains measured in the direction parallel to the applied force during tensile test compared with the predictions of the self-consistent model for different hkl reflections. Lattice strain measured in a) Al in $\mathrm{Al} / \mathrm{SiC}$, b) $\mathrm{SiC}$ in $\mathrm{Al} / \mathrm{SiC}$, and c) single phase Al - alloy.

The composite specimens were examined after T6 heat treatment, i.e., it was solution treated at $491^{\circ} \mathrm{C}$ for $6 \mathrm{~h}$ and then water quenched and artificially aged for $4 \mathrm{~h}$ at $191^{\circ} \mathrm{C}$. The specimen was subjected to in situ tensile tests. To perform comparative measurements a specimen of pure aluminium 2124 after T6 heat treatment was also prepared.

The in situ tensile test was performed with the time-of-flight (TOF) method on the EPSILONMDS instrument in the JINR in Dubna (Russia). The lattice strains were gathered at the ambient temperature with two detector sets enabling measurements in two directions: in the direction of applied force and the perpendicular direction. The measurements were performed for 8 stages of deformation, as well as for the initial and residual state of the material (each point was measured during about $22 \mathrm{~h}$, after stabilisation of the applied load). In Fig. 1 the results obtained in the direction of the applied load vs. sample strain are shown. The experimental stresses in the initial $\mathrm{Al} / \mathrm{SiC}_{\mathrm{p}}$ sample (and corresponding lattice strains seen for zero load in Figs. 1a and 1b) were determined in both phases using 9 detectors at EPSILON-MDS instrument. As the reference the stress free lattice parameter measured for $\mathrm{SiC}$ powder was used. This can be done because the structure of $\mathrm{SiC}$ does not undergo phase transformation during production and thermal treatment of the composite. On the other hand the lattice parameter of $\mathrm{Al}$ powder cannot be taken as the reference due to precipitation processes occurring in the alloy during thermal treatment. Therefore, the value of hydrostatic stress for Al matrix (and corresponding stress free parameter 
of $\mathrm{Al}$ ) was estimated from hydrostatic stress $\mathrm{SiC}$, assuming equilibrium of stresses between both phases.

The self-consistent modelling results are also presented in Fig. 1 for both measured samples (strains in the perpendicular direction are not shown here, but they also agree with model prediction). The single crystal elastic constants of pure aluminium and H6 polytype of SiC [13] were used in calculations. In the case of $\mathrm{Al} / \mathrm{SiC}_{\mathrm{p}}$ specimen, the agreement between experimental results and modelling was obtained for CRSS $\tau_{0 \mathrm{Al}}=120 \mathrm{MPa}$ and hardening parameter $\mathrm{H}_{\mathrm{Al}}=50 \mathrm{MPa}$ ( $\mathrm{SiC}$ particles remained elastic during whole deformation). The same values of model parameters were obtained from a comparative experiment performed for aluminium alloy 2124 subjected to the same thermal treatment (T6) as $\mathrm{Al} / \mathrm{SiC}_{\mathrm{p}}$ specimen.

On the basis of the lattice strain evolution in the $\mathrm{Al} / \mathrm{SiC}_{\mathrm{p}}$ composite it can be stated that the partitioning of load between $\mathrm{Al}$ matrix and $\mathrm{SiC}$ reinforcement is well predicted for advanced plastic deformation and after samples unloading. At the beginning of the tensile test, including elastic range and elastic-plastic transition, the relaxation of initial inter-phase stresses occurs, and this process is not reproduced by the model used. This effect can be caused by microdamage/decoupling process at the interfaces of $\mathrm{SiC}$ particles and $\mathrm{Al}$ matrix. Comparing the results for $\mathrm{Al} / \mathrm{SiC}_{\mathrm{p}}$ and $\mathrm{Al}$-alloy (singe phase) samples, nearly the same plastic behaviour was found for the aluminium phase (cf. Fig. 1a and 1c). It was also found that the evolution of lattice strains is similar for different hkl reflections in SiC phase (Fig. 1a), while significant difference between lattice strains in Al phase occurs during plastic deformation (Fig. 1b). The latter effect can be explained due to plastic anisotropy of $\mathrm{Al}$ grains and this is also seen in the case of single phase Al-alloy (Fig. 1c). The effects of anisotropy as well as the partitioning of the stresses between phases are well predicted by the model used.

\section{Damage process in stainless duplex steel}

The studied UR45N duplex steel is composed of ferrite and austenite, with the volume fraction of each phase approximately equal to $50 \%$. The steel was annealed at a temperature of $1050{ }^{\circ} \mathrm{C}$ and quenched with water to avoid precipitation of secondary phases. Finally, it was aged at $400^{\circ} \mathrm{C}$ for $1000 \mathrm{~h}$ and subsequently cooled in air at the ambient conditions.

Time of flight (TOF) neutron diffraction was used on the ENGIN-X instrument at the ISIS spallation neutron source to measure the lattice strains in the examined duplex steel. The size of the incident beam was limited by a slit ( $4 \mathrm{~mm}$ wide and $8 \mathrm{~mm}$ high), while the exit aperture of 4 $\mathrm{mm}$ was defined by radial collimators. The lattice strains in the direction of applied load along RD) were determined during in situ uniaxial tensile test at the ambient temperature. The measurements were made at a series of applied strains after stabilisation of the load subjected to the sample. The sample strains monitored by an extensometer were held constant during the measurement intervals of $5 \mathrm{~min}$. The lattice strains in the loading direction were determined for different hkl reflections and the calibration of the data for the large deformation range according to the method proposed by Baczmański et al. [10] was applied.

To identify the values of CRSS (critical resolved shear stresses, $\tau_{c}^{p h}$ ) for both phases, the model predicted strains $\left\langle\varepsilon_{R D}\right\rangle_{p h}$ (average values for each phase) were adjusted to the experimental ones, resulting from neutron measurements. To this end, the positions of two thresholds $\Gamma$ and $\Omega$ (Fig. 2), identified respectively as yield points for the austenite and for the ferrite phases, were compared. It allowed determination of the parameters of the Voce law for each phase, independently. The relative lattice strains were shown in Fig. 2, but the initial stresses between phases were taken into account in calculations (for details of model assumptions and numerical results see $[10,11])$. 
A significant decrease of lattice strains in the ferritic phase and a simultaneous increase of lattice strains in the austenite phase is observed above $\Lambda$ limit for the aged UR45N sample. It indicates an important relaxation of the stress in the ferritic phase, which is balanced by increasing the stress in the austenite. The observed experimental phenomenon can be predicted using our self-consistent model in which the ductile damage process is taken into account. It was assumed that at $\Lambda$ threshold the damage occurs only in the ferritic phase and the results of the model were fitted to experimental $\left\langle\varepsilon_{R D}\right\rangle_{p h}$ vs. $\Sigma_{R D}$ plots. A good agreement between the theoretical and experimental results was obtained for most of the measured hkl reflections if the damage process was taken into account. As it is seen in Fig. 2, a decrease of the lattice strains (and corresponding stress) for the ferritic phase and an increase in the lattice strains (and corresponding stress) for the austenitic phase at $\Lambda$ threshold indicate an initiation of the modelpredicted damage in the ferrite.

It was found that the rate of damage, characterized by $\dot{d}^{g}$, is proportional to the rate of equivalent strain $\dot{\varepsilon}_{\text {eq }}^{g}$ (because $n^{f e r}=0$ in Eq. 5). Such a stable evolution of damage in the ferritic phase is possible due to a transfer of the load into undamaged austenite, which compensates for a softening of the damaged ferritic phase. As shown in Fig. 2, a significant effect of the damage process is noticed for the $\Sigma_{R D}$ stresses above $\Lambda$ threshold.
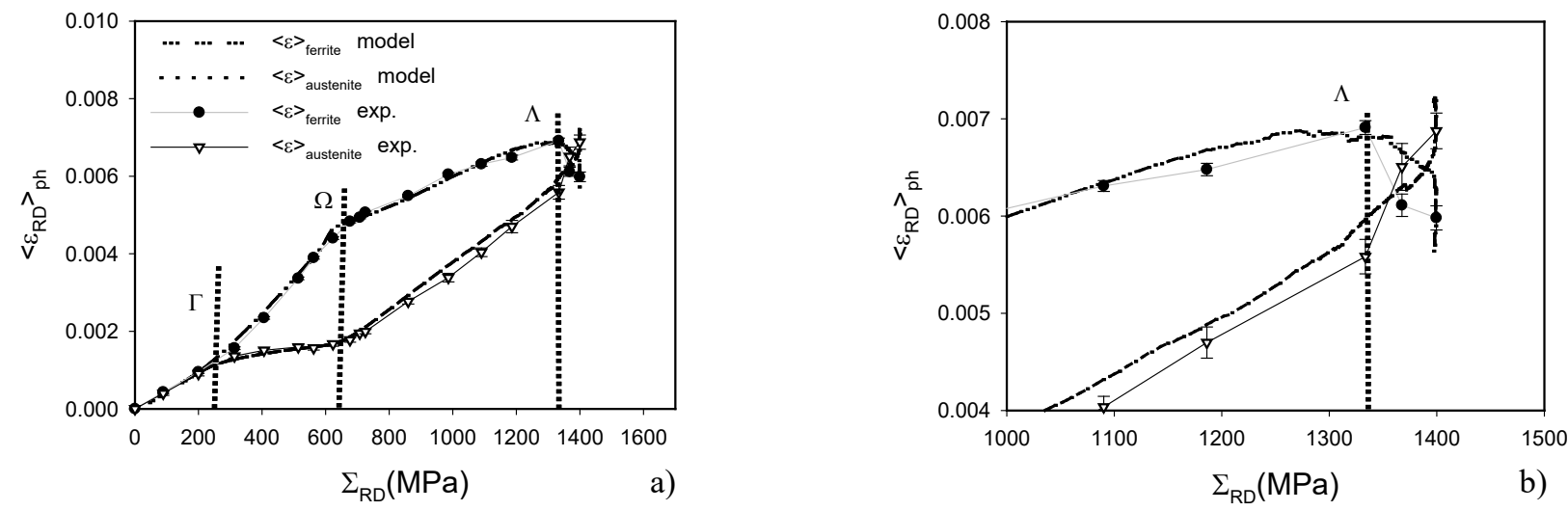

Fig. 2: Mean values of the measured elastic phase strains $\left\langle\varepsilon_{R D}\right\rangle_{p h}$ vs. applied stress $\Sigma_{R D}$ in the

UR45N sample compared with the phase strains calculated by the self-consistent model with damage prediction (a). On the right, magnification of the range close to sample fracture (b). The thresholds $\Gamma$ and $\Omega$ indicate the beginning of plasticity in austenite and ferrite, while $\Lambda$ defines the initiation of the damage process.

\section{Summary}

Comparison of the elastoplastic self-consistent model with measured lattice strains allows determining the micro-mechanical properties of aluminium alloy 2124 and the $\mathrm{Al} / \mathrm{SiC}_{\mathrm{p}}$ composite. The partitioning of the load between metal matrix and reinforcement were correctly predicted by the model.

It was shown that the developed version of the self-consistent model could be used to predict mechanical behaviour of both phases in duplex steel as well as the consequences of damage processes occurring in the ferritic phase. The model predictions are well correlated with the results of diffraction measurements performed in situ during tensile test.

\section{Acknowledgements}

The work was supported partly by the NCN - Polish National Center for Science, grants: No. UMO-2011/03/N/ST8/04058, DEC-2013/11/B/ST3/03787 and partly by the MNiSW - Polish 
Ministry of Science and Higher Education. Measurements at the ISIS (UK) neutron source were funded by a beamtime allocation (RB820145) from the STFC. Experiment in FLNP (JINR, Russia) was supported by beamtime allocations: 2014-10-14-18-51-38, 2015-04-18-15-20-06, 2016-04-14-19-53-04.

\section{References}

[1] J.D. Eshelby, The determination of the elastic field of an ellipsoidal inclusion and related problems, Proc. R. Soc. Lond. A 241 (1957) 376-396. https://doi.org/10.1098/rspa.1957.0133

[2] R. Hill, Continuum micromechanics of elastoplastic polycrystals, J. Mech. Phys. Solids 13 (1965) 89-101. https://doi.org/10.1016/0022-5096(65)90023-2

[3] P.A. Turner and C.N. Tomé, A study of residual stresses in Zircaloy-2with rod texture, Acta Metall. Mater. 42 (1994) 4143-4153. https://doi.org/10.1016/0956-7151(94)90191-0

[4] B. Clausen, T. Lorentzen, M.A.M. Bourke and M.R. Daymond, Lattice strain evolution during uniaxial tensile loading of stainless steel, Mater. Sci. Eng. A 259 (1999) 17-24. https://doi.org/10.1016/S0921-5093(98)00878-8

[5] M.R. Daymond and H.G. Priesmeyer, Elastoplastic deformation of ferritic steel and cementite studied by neutron diffraction and self-consistent modelling, Acta Mater. 50 (2002) 1613-1623. https://doi.org/10.1016/S1359-6454(02)00026-5

[6] C.J. Neil, J.A. Wollmershauser, B. Clausen, C.N. Tomé and S.R. Agnew, Modeling Lattice Strain Evolution at Finite Strains. Model Verification for Copper and Stainless Steel Using insitu Diffraction Measurement, Int. J. Plasticity $26 \quad$ (2010) 1772-1791. https://doi.org/10.1016/j.ijplas.2010.03.005

[7] P. Lipinski and M. Berveiller, Elastoplasticity of micro-inhomogeneous metals at large strains, Int. J. Plastic. 5 (1989) 149-172. https://doi.org/10.1016/0749-6419(89)90027-2

[8] A. Baczmański, R. Levy-Tubiana, M.E. Fitzpatrick and A. Lodini, Elastoplastic deformation of Al/SiCp metal-matrix composite studied by self-consistent modelling and neutron diffraction, Acta Mater. 52 (2004) 1565-1577. https://doi.org/10.1016/j.actamat.2003.12.002

[9] G. Franz, F. Abed-Meraim and M. Berveiller, Effect of microstructural and morphological parameters on the formability of BCC metal sheets, Steel Res. Int. 85 (2014) 980-987. https://doi.org/10.1002/srin.201300166

[10] A. Baczmański, L. Le Joncour, B. Panicaud, M. Francois, C. Braham, A.M. Paradowska, S. Wroński, S. Amara and R. Chiron, Neutron time-of-flight diffraction used to study aged duplex stainless steel at small and large deformation until sample fracture, J. Appl. Cryst. 44 (2011) 966-982. https://doi.org/10.1107/S0021889811025957

[11] A. Baczmański, Y. Zhao, E. Gadalińska, L. Le Joncour, S. Wroński, C. Braham, B. Panicaud, M. François, T. Buslaps and K. Soloducha, Elastoplastic deformation and damage process in duplex stainless steels studied using synchrotron and neutron diffractions in comparison with a self-consistent model, Int. J. Plast. 81 (2016) 102-122. https://doi.org/10.1016/j.ijplas.2016.01.018

[12] K. Saanouni and A. Abdul-Latif, Micromechanical Modeling Of Low-Cycle Fatigue Under Complex Loadings -Theoretical Formulation, Int. J. Plasticity 12 (1996) 1111-1121. https://doi.org/10.1016/S0749-6419(96)00043-5

[13] L. L. Snead, T. Nozawa, Y. Katoh, T.-S. Byun, S. Kondo and D.A Petti, Handbook of SiC properties for fuel performance modeling, J. Nucl. Mater. 371(2007) 329-377. https://doi.org/10.1016/j.jnucmat.2007.05.016 